\title{
CONTRIBUIÇÕES DOS ESTUDOS CULTURAIS PARA O CURRÍCULO DA EDUCAÇÃO FÍSICA'
}

\author{
DR. MARCOS GARCIA NEIRA \\ Livre-Docente em Metodologia do Ensino de Educação Física - USP \\ Doutor em Educação - USP \\ Professor Associado da Faculdade de Educação da USP (São Paulo - São Paulo - Brasil) \\ e-mail: mgneira@usp.br \\ DR. MÁRIO LUIZ FERRARI NUNES \\ Mestre em Educação - USP \\ Doutor em Educação - USP \\ Professor do Centro Universitário Ítalo-Brasileiro (São Paulo - São Paulo - Brasil) \\ e-mail:mlusa@uol.com.br
}

RESUMO

Exercendo uma influência cada vez maior nas análises da escolarização, os Estudos Culturais questionam que sujeito o projeto educativo hegemônico está formando, tendo em vista a atual sociedade multicultural e democrática. O presente artigo confronta esse campo teórico com o debate curricular da Educação Física, discute as formas pelas quais a cultura, permeada pelas relações de poder, concretiza políticas de identidade e interfere na prática pedagógica do componente. Evitando qualquer resposta definitiva, são apresentadas algumas contribuições para que se possa repensar a pedagogia da cultura corporal.

PALAVRAS-CHAVE: Estudos culturais; educação física; currículo; cultura.

I. Apoio financeiro do CNPq. Edital MCT/CNPq I5/2007. Processo n 480 I45/2007-5. 


\section{INTRODUÇÃO}

Neste começo de século, a democratização dos contextos educacionais remete, por um lado, ao questionamento dos currículos em vigor em grande parcela das escolas, dado seu tratamento privilegiado aos elementos provenientes da cultura dominante e, por outro, à necessária inserção e problematização daqueles conhecimentos advindos das culturas subordinadas (HALL, 2003).

As investigações sobre o currículo inspirados nos Estudos Culturais (EC) retificam seu papel decisivo na constituição de identidades. $\bigcirc$ acesso a certos conhecimentos e não outros, fazendo uso de certas atividades e não outras, termina por posicionar o aluno de uma determinada forma diante das "coisas" do mundo, influenciando fortemente as representações construídas. Nessa vertente, o currículo é concebido como campo de lutas para validação de modos de ser, o currículo forja identidades (SILVA, 2007).

Resultado de lutas travadas em meio a relações de poder tecidas no âmbito de contextos culturais e sociais o debate curricular subsidiado pelo campo teórico dos EC, pode-se dizer, tem recebido pouca atenção da comunidade acadêmica ${ }^{2}$ da Educação Física. Ou seja, os alertas emitidos por Silva (2000 e 2007) vêm sensibilizando gradativamente a área.

Considerando que toda decisão curricular é uma decisão política e que o currículo pode ser visto como um território de disputa em que diversos grupos atuam para validar conhecimentos (SILVA, 2007), é lícito afirmar que, ao promover o contato com determinados textos culturais, o currículo, além de viabilizar o acesso e uma gradativa compreensão dos conteúdos veiculados, influencia nas formas de interpretar o mundo, interagir e comunicar ideias e sentimentos.

A partir dos EC, o currículo da Educação Física também pode ser imaginado sob o modelo da textualidade. Enquanto texto, envolve práticas, estruturas institucionais e as complexas formas de atividade que estas requerem, condições legais e políticas de existência, determinados fluxos de poder e conhecimento, bem como uma organização semântica específica de múltiplos aspectos. Simultaneamente, esse texto só existe dentro de uma rede de relações intertextuais (a rede textual da cultura corporal, da cultura escolar, da prática pedagógica). Trata-se de uma entidade ontologicamente mista e para a qual não pode haver nenhuma forma "correta" ou privilegiada de leitura. Tal perspectiva questiona e ajuda a compreender o privilégio que determinados grupos possuem para fazer valer suas concepções de

2. O mapeamento realizado revelou que os estudos sobre o tema concentram-se no Grupo de Pesquisas em Educação Física Escolar da FEUSP (www.gpef.fe.usp.br). 
mundo, sociedade e práticas corporais, por exemplo. É justamente esse aspecto, mais do que qualquer outra coisa, que desencadeou o interesse por investigar as principais produções dos EC e garimpar suas contribuições mais relevantes, a fim de esboçar encaminhamentos para a construção e o desenvolvimento de currículos da Educação Física.

Em tempos de repetidas críticas aos diversos modelos curriculares em voga e diante da tentativa de transformar a realidade social brasileira tão desigual, os EC fornecem subsídios para afirmar o caráter político do currículo da Educação Física, ao incitar uma investigação mais rigorosa que busque desvelar como se dão os processos de identificação/diferenciação travados no seu interior. Para os EC, revelar os mecanismos pelos quais se constroem determinadas representações é o primeiro passo para reescrever os processos discursivos e alcançar a formação de outras identidades (NELSON; TREICHLER; GROSSBERG, 1995). Compreender melhor seus fundamentos é, como diz Corazza (2006), o primeiro passo para artistar currículos da Educação Física comprometidos com uma construção identitária mais democrática.

\section{OS ESTUDOS CULTURAIS: ORIGEM, OBJETIVOS E CAMPO DE ATUAÇÃO}

Desde sua gênese no movimento marxista denominado Nova Esquerda, na Inglaterra do segundo pós-guerra, à gradual incorporação do pensamento pósestruturalista, da teorização feminista, da teoria queer, do pós-colonialismo e do multiculturalismo, nos anos 1970 e 1980, os EC intervêm a favor da construção de significados e valores mais democráticos em uma sociedade marcada pela proliferação dos meios de comunicação de massa e pelas investidas de homogeneização cultural provenientes dos setores economicamente privilegiados.

Os EC surgem dos esforços de alguns intelectuais oriundos das classes populares britânicas para criticar a distorção empreendida pelos membros da denominada alta cultura com relação à cultura popular e à cultura de massas. Em outras palavras, trata-se de uma reação à tendência elitista da concepção de cultura. Enfaticamente, seus representantes defendem que no seio da classe popular não há somente maugosto, passividade, submissão e assimilação, mas também resistência e produção.

Sob influências dos movimentos de certos grupos sociais que lutam pela valorização da sua leitura de mundo, contrapondo-se às barreiras que impedem o acesso dos desprivilegiados a uma sociedade democrática, os EC defendem uma educação em que as pessoas comuns, os representantes do povo, possam ter seus conhecimentos validados e seus interesses contemplados. $\bigcirc$ projeto dos EC é possibilitar aos grupos em desvantagem uma participação equitativa, mesmo 
em uma cultura aonde quem determina a moda, bom gosto, comportamento, moral, conhecimento e linguagem, encarna um pensamento elitista que segrega as pessoas. Cultura erudita e popular, alta e baixa, burguesa e operária, configuram escalas hierárquicas em que o primeiro termo é visto como expressão máxima da produção ou do espírito humano, o que de melhor o homem já produziu e no segundo se encaixam a oposição e as produções menores, desqualificadas, irrelevantes e responsáveis pelos empecilhos ao desenvolvimento da espécie humana. Nesta lógica, a produção cultural erudita, alta e burguesa deveria ser cultivada para afastar a barbárie dos grupos populares, cujo modo de ser se caracterizaria pelo mau-gosto, desordem e violência social, ignorância científica e política. Nesta lógica, insistimos, somente a harmonia e a beleza das primeiras poderiam afastar o povo de sua pseudo-condição "sub-humana". Em termos pragmáticos, o povo deveria ser aculturado ou afastado, marginalizado.

Com o advento dos EC, o conceito de cultura sofreu transformações, ampliou seu espectro de análise e incorporou os domínios do popular. Antes visto como algo a ser combatido e superado para a evolução da humanidade, "popular", na atualidade, oscila entre variados significados que podem indicar desde tradição, folclore e práticas da maioria até minimalista, despojado, cult etc. $\bigcirc$ conceito "popular", como se nota, perdeu os significados atribuídos por um grupo autodenominado superior que via a cultura como elemento de distinção social e queria realçar erudição, tradição literária, artística e estética, para contemplar o gosto das multidões, agregando outros sentidos. Os EC convidam ao debate a cultura de massa, elemento típico da indústria cultural e da sociedade techno, bem como reconhecem e valorizam os artefatos de quaisquer outros grupos, como a cultura infantil, juvenil, a tecnocultura, a cultura gay, empresarial, escolar, negra, étnica, acadêmica etc. A cultura perdeu sua condição maiúscula e singular e ganhou a pluralidade das culturas.

Ao longo do século $X X$, vários movimentos tentaram fazer frente a um suposto declínio cultural provocado pelo avanço da cultura de massas e do seu aclamado nivelamento por baixo. Para tanto, foram incrementadas ações nas escolas, universidades e nos mais variados ambientes sociais, em defesa de um estado cultivado de espírito como oposição à exterioridade materialista da civilização. As denominadas grandes obras literárias, artísticas e musicais, determinados idiomas estrangeiros, certas práticas corporais, entre outros produtos, foram amplamente divulgados tanto nas instituições de formação quanto no espaço público, sob o discurso de "levar a cultura ao povo".

Os EC investem contra qualquer imposição hierárquica de gostos e sentidos. Apesar de atuarem em várias frentes, sua ênfase recai na importância da análise das produções culturais de uma sociedade e de seus diferentes textos e práticas, a fim 
de entender o comportamento e as ideias compartilhadas pelas pessoas. Os EC realçam o aspecto político do significado de cultura e se engajam nas propostas de democratização das relações de poder e transformação social, pois, afinal, "estão profundamente preocupados com a relação entre cultura, conhecimento e poder" (GIROUX, 1995, p. 86).

Para Schwarz (2000), são dois os determinantes históricos para a emergência e o desenvolvimento dos EC. Primeiro, o fim do imperialismo britânico, que propiciou a migração de seus ex-colonos para sua "casa imaginada", a Inglaterra, fomentando novas preocupações políticas na organização daquela sociedade. Essa diáspora colocou frente a frente intelectuais de origem colonial e seus colegas britânicos. O olhar do colonizado produziu conceitos, ideias e críticas ao pensamento acadêmico colonialista.

A reorganização de todo o campo cultural a partir do impacto da expansão do capitalismo é, segundo o autor, outro fator determinante para a eclosão dos EC. $\mathrm{O}$ acesso à TV e à publicidade foi democratizado, disseminando variadas imagens e textos culturais que enfraqueceram o poder cultural das elites. Veja-se, por exemplo, o borramento das fronteiras entre alta e baixa cultura, antes claramente delimitadas pelo usufruto de artefatos culturais. Hoje, a literatura de ficção científica, a música clássica, o balé, o esporte amador, etc., se deparam com as produções da indústria cultural como os filmes de George Lucas, a ópera rock Hair, o balé contemporâneo e o esporte profissional. Estes artefatos da cultura de massa ajudaram a tornar opaca a linha que separava alta e baixa cultura, produzindo novos deslocamentos e hibridismos entre os grupos, novas imagens e sentidos, enfim, outras fronteiras.

As contribuições dos EC rompem com a ideia de que a produção do conhecimento é fruto da continuidade natural da história ou de embates acadêmicos e epistemológicos que buscam a melhor forma de explicar a realidade. Os EC desdobraram a simplicidade desta explicação para a complexidade das relações sociais que nos atravessam a tudo, a todos e em todas as direções, entretecendo o tecido social.

O projeto político dos EC escapa da imparcialidade. Tomam partido dos grupos desprivilegiados nas relações de poder envolvidos na luta por significação. Suas análises promovem a intervenção social. Seu compromisso é examinar qualquer prática cultural a partir da sua constituição e do seu envolvimento com e no interior das relações de poder (NELSON; TREICHER; GROSSBERG, 1995). Os EC se recusam a desvincular a política do poder de definir as experiências que valem e, também, dos modos apresentados como corretos e que legitimam certas identidades. Suas análises visam contribuir para o desenvolvimento de uma cultura pública e uma sociedade democrática. Situam seus métodos de trabalho na inter-relação entre 
as representações simbólicas, a vida cotidiana e as relações materiais de poder, a fim de capacitar as pessoas para atuar coletivamente nos espaços públicos e melhorar suas condições de existência no seio de uma sociedade democrática.

Os EC têm início em meio ao debate pós-moderno, sobretudo na percepção do fim das grandes narrativas que constituíram o projeto moderno e a radicalização do papel da linguagem na definição da realidade. Diante da desconfiança que o pósmodernismo desferiu às certezas da razão, os EC negam as verdades absolutas. Exigem que a explicação do real não seja decorrente de uma única visão. Isso implica no questionamento das noções universais de homem e mulher, mundo e sociedade e no questionamento das práticas que insistem em afirmar essa condição.

Para alguns, os EC são celebrados como um novo campo teórico capaz de pensar a sociedade em uma época cada vez mais instável para a sistematização de ideias, a era da cultura. Também existem aqueles que criticam seu projeto e denunciam suas intenções de demolir a tradição cultural da humanidade, trocando o estudo das grandes obras-primas pela análise dos fenômenos de massa. Enfim, assumindo todos os riscos pela ousadia, podemos resumir as preocupações dos EC em uma só questão: na era da globalização, mídia e proliferação de imagens, como a cultura circula e penetra em todos os cantos, formando e informando seus sujeitos?

\section{OS ESTUDOS CULTURAIS E O CONCEITO DE CULTURA}

O conceito de cultura é extremamente complexo e polissêmico. Na contemporaneidade, as análises deslocaram o homem, com sua consciência e sua subjetividade, do centro das decisões e explicações a respeito do real. A crise da modernidade (e do sujeito da modernidade) e o pós-modernismo abriram as portas para que a linguagem fosse vista como possibilidade explicativa dos fenômenos naturais e das ações humanas. Uma vez que a linguagem é um veículo de comunicação dos significados construídos culturalmente, estava adubado o terreno para a centralidade da cultura.

Assumindo essa perspectiva, para Hall (1997) o conceito de cultura decorre de dois movimentos. Primeiro, uma aproximação com a visão antropológica, como toda e qualquer prática social produzida pelo homem; e, segundo, um contra-movimento dessa definição, questionando seu aspecto universal. $\bigcirc$ autor propõe um olhar histórico e o diálogo com outros saberes para a sua compreensão, incorporando conceitos como formação social, poder, regulação, dominação, subordinação, resistência e luta. $\bigcirc$ termo cultura passa a ser compreendido como forma de vida (línguas, instituições, estruturas de poder) e práticas sociais (textos, cânones, arquitetura, mercadorias etc.). 
Os EC enfatizam a vida cotidiana das pessoas comuns, compreendendo suas produções e sentidos. $O$ ponto central é a análise dos textos ${ }^{3}$ e das representações construídos para interpretar as práticas culturais vividas pelos diversos grupos. Nos EC a cultura é vista como um território contestado atravessado por relações de poder, um campo de luta pela definição dos significados e, por essa razão, como campo de intervenção política.

As sociedades capitalistas promovem a desigualdade entre etnias, gêneros, gerações, classes e sexualidades diversas, sendo a cultura o campo central em que essas distinções hierárquicas de poder e possibilidades são definidas. É nesse campo contestado que se dá a luta pela significação, espaço em que os grupos subjugados procuram fazer frente às imposições dos significados que sustentam os interesses dos grupos dominantes (HALL, 1997). Por assim dizer, os textos culturais são o próprio local em que os significados são disputados, negociados, partilhados, divulgados e fixados. Com o mesmo sentido, pensadores como García Canclini, Frederic Jameson, David Harvey, Homi Bhabha, entre outros, afirmam que a cultura não pode ser mais compreendida apenas como acumulação ou transmissão de saberes, nem tampouco como produção estética, intelectual ou espiritual. Precisa ser compreendida e analisada a partir de seu vasto alcance na constituição de todos os aspectos da vida das pessoas, ou seja, a cultura está no centro.

A centralidade da cultura tem uma dimensão substantiva, o lugar em que se organizam as relações na sociedade em qualquer momento histórico; e uma dimensão epistemológica denominada de virada cultural. A virada cultural se refere ao poder que engendra os discursos que operam no circuito cultural e que informam e transformam nossa compreensão do mundo. Significa que as notícias divulgadas nas mídias, os conceitos apresentados nos livros didáticos, as músicas de um grupo de pagode, a coreografia de uma dança, o cozinhar e a própria cozinha, o design de um automóvel ou as aulas de Educação Física não são apenas artefatos culturais. São também artefatos produtivos que inventam sentidos, produzem identidades e representações que circulam e operam nas arenas contestadas da cultura, negociando os significados que determinam as hierarquias: quem pode e quem não pode, quem é quem e como se deve ser. Na ótica de Hall (1997), a luta por poder deixa de ser física e passa a ser cada vez mais simbólica e discursiva. A luta por poder faz da linguagem uma arena política.

3. Silva (2000) explica que em termos gerais, um texto é qualquer conjunto de signos dotados de algum sentido. Segundo Derrida (2002), na análise pós-estruturalista, não há nada fora do texto. Um texto é uma gama diversificada de artefatos linguísticos como: um livro didático, um filme, a sala de aula, uma manifestação da cultura como: a música, a dança, uma propaganda etc. 
Hall ( 1997) afirma que cultura é toda e qualquer ação social que expressa ou comunica um significado, tanto para quem dela participa, quanto para quem observa. A cultura é uma prática de significação. Cada atividade social cria e precisa de um universo próprio de significados e práticas, isto é, sua própria cultura. A cultura, assim entendida, constitui-se em uma relação social permeada pela luta para definir o que está, ou não, correto e o como se deve, ou não, ser, pensar e agir. Podemos dizer que a escola, a rua, o clube, o ambiente de trabalho, o hospital, a família, o futebol profissional, de rua ou de várzea etc. constituem-se em textos, em campos culturais com significados próprios negociados em um constante, transitório e indefinido jogo de poder e em luta por poder. Por aceitarem essa definição, Neira e Nunes (2009) vão postular que a cultura corporal assume a dimensão de um território de conflito expresso na intencionalidade comunicativa do movimento humano. Não fosse assim, todas as práticas corporais (produtos da cultura) seriam igualmente representadas, legitimadas e validadas no currículo escolar (lugar de confronto de culturas).

Logo se vê que a cultura está localizada sobre fronteiras aonde se tocam e entrecruzam outras significações. É na fronteira que ocorre toda a ação dinâmica da cultura pela imposição ideológica de seus significados. A luta das culturas é pelo controle da informaação e do conhecimento que permite ao homem interpretar e intervir na realidade. A cultura é o campo de luta pelo poder de definir a realidade. Logo, para os EC, a realidade é fruto dos significados construídos nas relações sociais, nas relações de poder.

Hall (1997) esclarece que a cultura é um sistema simbólico que atribui significados às coisas, mediante mecanismos classificatórios que ajudam a estabilizar as relações na medida em que se criam fronteiras para excluir o que está fora do lugar e da ordem e, assim, criar homogeneidade. Implica em esquecer eventuais inconsistências internas, contradições e conflitos que marcaram a validação dos significados. É o que transmite a impressão de naturalidade e impossibilidade de mudanças. Um fato que incomode, a chamada cultura de fronteiras, representa uma perturbação que precisa ser eliminada sob o risco de atrapalhar os padrões estabelecidos, o próprio processo de classificação e, logo, de significação. Decorre daí a tendência em rejeitar qualquer proposta de modificação do que foi culturalmente estabelecido, tal como certas formas de educar os filhos, cuidar da saúde, relacionar-se com o cônjuge, trabalhar, dançar, ensinar etc.

O jogo do poder cultural para definir significados e marcar fronteiras fica mais claro quando se analisam os artefatos da cultura corporal. $\mathrm{Na}$ arena de lutas pela imposição de significados, alguns podem ser mantidos por muito tempo à margem da sociedade (capoeira, funk, determinadas brincadeiras, algumas lutas, etc). Estar à margem é estar permanentemente na fronteira, consequentemente, esclarece Hall (2003), trata-se de um elemento perturbador ou desestabilizador da cultura. 
A trajetória da capoeira é um bom exemplo. Após anos de luta e marginalizações, hoje é tratada como símbolo nacional cuja prática invadiu escolas, clubes, academias da elite etc. Isso não foi obra do acaso, mas sim, por meio de lutas por significação. Como artefato cultural, a capoeira fez mais do que ampliar seus espaços atuação, ela propiciou uma ação política da cultura negra. Trata-se de um movimento permanente no jogo do poder cultural que caracteriza a maior parte das práticas da cultura corporal e de seus representantes. Basta que se verifique o modo como as práticas corporais pertencentes a grupos não hegemônicos são incorporadas e aproveitadas pelos setores dominantes. É comum o apagamento da história das lutas e origens de várias manifestações culturais em troca da validação por meio de outros significados propagados pela ciência moderna - alusão dos benefícios à saúde ou ao desenvolvimento motor que a capoeira, algumas brincadeiras ou danças propiciam; a comprovação da ciência ocidental com relação aos fundamentos da yoga ou a valorização da prática do tai-chi para melhorar a concentração nas atividades laborais. Para piorar o quadro, muitas vezes os próprios representantes dessas práticas culturais não percebem as intenções subjacentes às investidas dos grupos em evidência e reproduzem inocentemente seus discursos.

Outro exemplo desse fenômeno é a conhecida tentativa de fazer convergir várias tendências da Educação Física escolar em uma única proposta, conforme denunciaram Neira e Nunes (2009). Haja vista a repetição discursiva sobre o "uso do que há de melhor em cada uma". Ora, se atentarmos para o que foi discutido, tal argumentação mostra-se frágil quando se questiona quem tem o poder de selecionar e classificar o que é bom em cada vertente. Aqui se vê uma tentativa de incorporação das práticas transgressoras e de oposição aos ditames conservadores do pensamento neoliberal, mediante o enfraquecimento dos significados anunciados pelas tendências críticas do componente. Se "misturarmos" objetivos e atividades desenvolvimentistas, psicomotoras, da saúde e críticas, não é difícil prever quais sairão fortalecidas. Os defensores dessa pasteurização afirmam que todas as propostas são interessantes para a formação humana, aliás, defendem uma noção de humanidade que comunga com seus interesses.

\section{OS ESTUDOS CULTURAIS E O CONCEITO DE IDENTIDADE}

As modificações culturais desestabilizam as estruturas sociais que ancoram os sujeitos, causando mudanças nos modos de ser, sentir e pensar. Na visão de Hall ( 1997), a linguagem assume função primordial quanto à estrutura e organização das sociedades, dada a intensificação do fluxo de produção, circulação e trocas culturais. A cultura, por sua vez, exerce um papel constitutivo em todos os aspectos da vida 
social, pois todas as práticas sociais comunicam um significado. Hall enfatiza que a centralidade da cultura é um fator constituinte do sujeito, pois a identidade é resultado do processo de identificação que os discursos culturais fornecem, posicionando os sujeitos nos sistemas simbólicos, ou seja, no interior de cada cultura. $\bigcirc$ autor assevera que a centralidade da cultura dissolveu a fronteira entre a subjetividade e a identidade, entre o psíquico e o social. Qualquer artefato cultural, portanto, implica processos de representação, identidade, produção, consumo e regulação.

Diante desses argumentos, a questão da identidade e das formas como elas são representadas tornam-se fundamentais para os EC. $O$ que interessa saber é como as identidades foram produzidas e como as representações que se fazem delas as afetam e imobilizam. O importante é saber como os discursos e práticas atuam de modo a levar os sujeitos a assumirem certas posições no sistema social e como os sujeitos são construídos por esses mesmos discursos e práticas. Em outras palavras, é preciso conhecer o processo de identificação.

Como explicar o que é ser brasileiro? Por meio da imagem do habitante das metrópoles que trabalha nos grandes centros empresariais ou do jangadeiro que reside em um povoado litorâneo e enfrenta o sol escaldante diariamente; da mulher sedutora das propagandas de cerveja ou daquela que carrega latas d'água e trouxas de roupa; do garoto que faz malabarismos nos cruzamentos dos centros urbanos ou daquele que frequenta a escola desde a primeira infância? Também vale dizer: povo religioso, acolhedor, batalhador, fã do futebol, que convive com o diferente etc. Não importa a imagem escolhida, o que importa são seus efeitos. As escolhas aqui realizadas e tantas outras possíveis indicam o significado da imposição de identidades a certos grupos culturais por meio de práticas discursivas que constroem representações. Em alguns momentos, o sujeito poderá identificar-se ou rejeitar qualquer uma. Mesmo que jamais se sinta plenamente representado, os efeitos ecoarão nos momentos em que se depara com uma identidade, o que implicará na assunção ou resistência às posições que ela incita.

Em se tratando da Educação Física, o que importa saber é como o currículo, suas práticas e sistemas simbólicos, instam os sujeitos a assumirem determinadas posições, afirmando as identidades projetadas como as ideais para compor o quadro social e enunciando a diferença, para aqueles que precisam ser corrigidos, transformados ou, caso resistam ou não consigam adaptar-se, marginalizados.

Ao analisar a história de vida de pessoas submetidas ao currículo esportivo ${ }^{4}$, Nunes (2006) observou que os rituais, discursos e práticas presentes neste modelo

4. Denominação atribuída por Nunes e Rúbio (2008) às propostas curriculares da Educação Física que recorrem prioritariamente ao ensino dos esportes visando a formação de identidades "vencedoras". 
curricular instigam seus sujeitos a assumirem certos modos de ser, validando aqueles que atuam em conformidade com o sistema simbólico (esporte) divulgado - a identidade - e afastando aqueles que resistiram às suas imposições - os diferentes.

$\mathrm{Na}$ direção do silenciamento das identidades dos grupos culturais desprivilegiados, Chaim (2007), ao investigar o cotidiano de jovens de comunidades da periferia paulistana, constatou por um lado, a abundância de práticas corporais no universo juvenil e, por outro, sua total ausência no currículo da Educação Física. Tal "negligência", afirma o autor, contribuiu para o desinteresse e conflitos envolvendo professores e alunos.

$\mathrm{Na}$ visão dos $\mathrm{EC}$, as relações sociais assimétricas de poder estabelecem o jeito certo de ser e afirmam as experiências que valem, configurando tanto a identidade, com seu inverso, a diferença. Por meio de uma longa imersão na cultura esportiva ${ }^{5}$, os estudantes são levados a valorizar as técnicas esportivas e a admirar aqueles que as executam de acordo com a norma. Mesmo que o patrimônio cultural corporal adquirido pelas experiências extra-escolares seja amplo e variado, sua ausência no currículo acaba sendo traduzida como conhecimentos de pouca importância. É neste jogo que os grupos que detém o poder simbólico de definir o que é válido afirmam para si a condição de identidade e padrão a ser seguido e representam o Outro como o diferente, alguém a ser corrigido ou deixado à margem das decisões sociais.

\section{CONSIDERAÇÕES PARA O CURRÍCULO DA EDUCAÇÃO FÍSICA}

Os EC alertam que a possibilidade da transformação social passa necessariamente pelas políticas de identidade, ou seja, pela prática de possibilitar ao Outro, ao diferente, a oportunidade para construir sua própria representação na cultura e divulgá-la. Ao lado de outras, o currículo pode constituir-se como arena política para semear a transformação. Afinal, no dizer de Silva (2000), assim como a cultura, o currículo é um campo de luta em torno da significação e da identidade.

Nas análises dos EC, o currículo é um campo cultural sujeito à disputa e à interpretação, no qual os diferentes grupos tentam estabelecer sua hegemonia e projetar as identidades desejáveis. O currículo é um artefato cultural, pois, a "instituição" do currículo é uma invenção social como qualquer outra e seu "conteúdo", uma construção social. Como toda construção social, o currículo não pode ser compreendido sem a análise das relações de poder que operaram para construir

5. Nas trajetórias de sujeitos investigados por Nunes (2006), o esporte era a temática predominante nas aulas de Educação Física. 
determinada proposta curricular e não outra, onde se incluem determinados conhecimentos e não outros.

$\mathrm{Na}$ ótica cultural se destacam as estreitas conexões entre a característica construída do currículo, a produção de identidades culturais e a descrição das diversas formas de conhecimento corporificadas. É importante frisar que, para os EC, o conhecimento não é uma revelação ou reflexo da natureza ou da realidade, mas o resultado de um processo de criação e interpretação social. Todas as formas de conhecimento são, portanto, resultado de aparatos - discursos, práticas, instituições, instrumentos, paradigmas - que viabilizaram sua construção como tal.

Uma concepção de currículo inspirada nos EC equipara, de certa forma, o conhecimento propriamente escolar com o conhecimento cotidiano da comunidade. Desse ponto de vista, ambos expressam significados social e culturalmente construídos, ambos buscam influenciar e modificar as pessoas e estão envolvidas por complexas relações de poder. Em outras palavras, a cultura escolar e a cultura paralela à escola estão permeadas por uma economia do afeto que busca produzir um certo tipo de subjetividade e identidade (SILVA, 2007).

Finalmente, num mundo social e cultural cada vez mais complexo onde a característica mais saliente é a incerteza e a instabilidade; num mundo atravessado pelo conflito e pelo confronto; num mundo no qual as questões de diferença e da identidade se tornam centrais, é de se esperar que as contribuições dos EC possam encontrar um espaço importante nas perspectivas sobre o currículo ou, ao menos, na contestação dos currículos inspirados nas pedagogias acríticas. Queiram ou não, para o bem ou para o mal, a sociedade do século $X X \mid$ vive sob um certo esgotamento das metanarrativas iluministas e das formas de vida moderna em seu plano existencial (BAUMANN, 1999).

Uma das consequências do enfoque cultural para a teorização curricular consiste na diminuição das fronteiras entre, de um lado, o conhecimento acadêmico escolar e, de outro, o conhecimento cotidiano e o conhecimento da cultura de massa. Conforme se viu, todo conhecimento, na medida em que se constitui num sistema de significação, é cultural. Além disso, como sistema de significação, todo conhecimento está estreitamente vinculado com relações de poder. Ao abordar todo e qualquer conhecimento como produto do processo cultural orientado por relações sociais assimétricas, a perspectiva dos EC efetua uma espécie de equivalência entre as diferentes formas culturais. De certo modo, pode-se dizer que os EC ressignificam o fazer pedagógico, tornando central na cena educativa questões como, culturas, identidade, discurso, representação e poder. $\bigcirc$ estudo de Neira (2008), por exemplo, mostrou como o processo de identificação influencia o fazer escolar. Experimentando uma prática pedagógica orientada a partir da cultura dos alunos, 
percebeu o reconhecimento dos envolvidos no processo, tanto com relação à escola, enquanto espaço de convivência, ensino e aprendizagem, quanto das identidades culturais dos grupos cujas manifestações foram problematizadas no currículo.

Ao equiparar a noção de cultura popular e cultura acadêmica, as contribuições dos EC sugerem que as temáticas advindas da comunidade são tão dignas de figurar no currículo escolar quanto aquelas originadas nos setores privilegiados. $\bigcirc$ que subverte a exclusividade de práticas corporais completamente afastadas do universo cultural dos alunos. Afinal, a trajetória curricular do componente quando não conferiu exclusividade aos temas nascituros na cultura dominante, tratou de prestigiar manifestações próprias da cultura escolar, inventadas com o objetivo primordial de transmitir determinados conhecimentos. É o caso, por exemplo, dos jogos pré-desportivos, das sequências pedagógicas, dos contestes etc., presentes, ainda hoje, nos currículos esportivo, psicomotor e desenvolvimentista (NEIRA; NUNES, 2009).

O caráter pós-disciplinar dos EC permite afirmar que a prática pedagógica da Educação Física não pode seguir influenciada tão somente pela Psicologia, pois as análises sociais contribuirão para alinhar o currículo à contemporaneidade. Ao planejar ações didáticas visando garantir a aprendizagem de todos, inserindo-os em estágios universais de desenvolvimento, corre-se o risco de reforçar as diferenças. Como se disse, os alunos estão no mundo que forma e informa. O professor pode discursar sobre a importância da participação coletiva, do respeito aos tempos de aprendizagem de cada um e garantir que todos peguem na bola, dancem ou brinquem. Porém, se não for analisado e discutido o design competitivo, materialista e imagético da sociedade pós-moderna, promotora de uma cultura que afirma os melhores como eficientes, sem dúvida, o significado pedagógico das atividades propostas estará comprometido. A simples oferta de práticas corporais visando o alcance de objetivos comportamentais implica em uma experiência formativa que concretiza, com certa excelência, as relações de saber-poder e as identidades projetadas pelas pedagogias tecnicistas nas quais se inspiraram.

A análise cultural revelará que essas atividades carecem de sentido numa escola compromissada com a democratização do patrimônio cultural. Tal pedagogia insípida serve, no máximo, como meio para o desenvolvimento de comportamentos e identidades que a cultura acadêmica julga necessários a um bom desempenho social e desconsidera a história e as vozes de quem (também) constitui a sociedade. Algo bem diferente ocorrerá se os alunos, além de jogar handebol, forem incitados a interpretar sua gestualidade, analisar sua história, forma, intenção política, descobrir quem são e como pensam seus jogadores e técnicos e tantas outras marcas presentes em qualquer prática corporal. 


\section{Contributions of Cultural Studies to Physical Education curriculum}

ABSTRACT: With the increase of its influence in the school process analyzes, the Cultural Studies question what kind of individual the hegemonic educative project is forming, considering the current multicultural and democratic society. The present article confronts this theoretical field with the Physical Education curriculum debate, discusses in which ways the culture, interrelating with the relations of power, establishes the identity policies interfering in the pedagogical practices of the discipline. Avoiding any definite answer, some contributions are presented in order to enable a contemplation of the corporal culture pedagogy.

KEYWORDS: Cultural studies; physical education; curriculum; culture.

\section{Contribuciones de los Estudios Culturales para el currículo de la Educación Física}

RESUMEN: Al ampliar su influencia sobre los análisis de la escolarización, los Estudios Culturales han puesto la pregunta acerca del sujeto bajo el proyecto educativo hegemónico presente en la actual sociedad multicultural y democrática. Este artículo enfrenta este campo teórico con el debate curricular de la Educación Física, apunta las maneras por las cuales la cultura, atravesada por las relaciones de poder, concretiza políticas de identidad e interfiere en la práctica pedagógica de este componente. Aquí son presentadas algunas contribuciones para que sea posible repensar la pedagogía de la cultura cultural, sin apuntar cualquier respuesta definitiva.

PALABRAS-CLAVE: Estudios Culturales; educación física; currículo; cultura.

\section{REFERÊNCIAS BIBLIOGRÁFICAS}

BAUMAN, Z. Globalização: as consequências humanas. Rio de Janeiro: Jorge Zahar, 1999.

CHAIM, C, I. Cultura corporal juvenil da periferia paulistana: subsídios para construção de um currículo de Educação Física. 2007. 99 f. Dissertação (Mestrado em Educação) - Faculdade de Educação, Universidade de São Paulo, São Paulo, 2007.

CORAZZA, S. M. Artistagens: filosofia da diferença e educação. Belo Horizonte: Autêntica, 2006.

DERRIDA, J. A escritura e a diferença. São Paulo: Perspectiva, 2002.

GIROUX, H. "Praticando Estudos Culturais nas Faculdades de Educação". In: SILVA, T.T. (Org.) Alienígenas na sala de aula: uma introdução aos estudos culturais em educação. Rio de Janeiro: Vozes, 1995. p. 85- 103.

HALL, S. A centralidade da cultura: notas sobre as revoluções de nosso tempo. Educação e realidade, Porto Alegre, v. 22, n. 02, p. I 5-46, jul./dez. 1997. 
Da diáspora: identidades e mediações culturais. Belo Horizonte: Editora UFMG, 2003.

NEIRA, M. G. A Cultura Corporal Popular como conteúdo do currículo multicultural da Educação Física. Pensar a prática, Goiânia, v. I I , n. I., p. 8I-90, jan./mar. 2008.

NEIRA, M. G.; NUNES, M. L. F. Educação Física, currículo e cultura. São Paulo: Phorte, 2009.

NUNES, M. L. F. Educação Física e esporte escolar: poder, identidade e diferença. 2006. 206 f. Dissertação (Mestrado em Educação) - Faculdade de Educação, Universidade de São Paulo, São Paulo, 2006.

NUNES, M. L. F. e RÚBIO, K. O(s) currículo(s) da Educação Física e a identidade dos seus sujeitos. Currículo sem fronteiras, Mangualde, Portugal, v. 8, n. 2, p. 55-77, jul./dez. 2008.

NELSON, C.; TREICHLER, P. A.; GROSSBERG, L. "Estudos Culturais: uma introdução". In: SILVA, T.T. (Org.) Alienígenas na sala de aula: uma introdução aos estudos culturais em educação. Rio de Janeiro: Vozes, 1995. p. 07-38.

SCHWARZ, B. Onde estão os cultural studies? Revista de Comunicação e Linguagens, Lisboa, n. 28, p. 42-64, out., 2000.

SILVA, T. T. A produção social da identidade e da diferença. In: Identidade e diferença: a perspectiva dos Estudos Culturais. Petrópolis: Vozes, 2000.

Documentos de identidade: uma introdução às teorias do currículo. Belo

Horizonte: Autêntica, 2007.

Recebido: 24 ago. 2010

Aprovado: 04 dez. 2010

Endereço para correspondência:

Marcos Garcia Neira

Faculdade de Educação da USP

Av. da Universidade, 308

Cidade Universitária - São Paulo - SP

CEP - 05508-000 